\title{
A concealed cause of recurrent renal failure in a patient with juvenile chronic arthritis
}

\author{
J Hamilton, P Balint, M Field, R D Sturrock
}

\section{Case report}

A 20 year old man with a 17 year history of systemic onset juvenile chronic arthritis (JCA) was admitted with a fever of $38.2^{\circ} \mathrm{C}$ with increasing joint pain especially at the right hip. Numerous disease modifying agents including corticosteroids had been tried previously, but despite this his disease remained sub-optimally controlled and at age 14 he was diagnosed as having renal amyloid on the basis of proteinuria and an iodine-123-serum amyloid $\mathrm{P}$ $\left({ }^{123} \mathrm{I}\right.$-SAP) scan and started on treatment with chlorambucil. Bilateral hip replacements were performed but revision surgery was required to the right hip one year later complicated by low grade sepsis with staphylococcus epidermidis. Although mobility remained significantly impaired becuse of the consequences of his hip disease, by the age of 17 sequential ${ }^{123}$ I-SAP scanning demonstrated that the amyloid load was small. At that stage he had little in the way of active joint disease. The chlorambucil dose was tapered and stopped. He subsequently defaulted from medical follow up.

On admission drug treatment consisted of metoprolol only. His blood pressure (BP) was $130 / 80 \mathrm{~mm} \mathrm{Hg}$. Full blood count (FBC) including lymphocyte count was normal. Clinical examination showed mechanical impairment of the joints but no active synovitis. Flucloxacillin $1 \mathrm{~g}$, four times daily and gentamicin 2.5 $\mathrm{mg} / \mathrm{kg} /$ day amounting to $50 \mathrm{mg}$ twice daily for a body weight of $42 \mathrm{~kg}$ was started to cover the possibility of recurrent hip sepsis. Two days later he became hypotensive (BP 90/60 $\mathrm{mm} \mathrm{Hg}$ ) and anuric with deteriorating renal function-urea $14.5 \mathrm{mmol} / 1$ (normal range $2.5-8 \mathrm{mmol} / \mathrm{l}$ ) and creatinine $320 \mu \mathrm{mol} / 1$ (normal range 40-130 $\mu \mathrm{mol} / \mathrm{l}$ ) compared with a urea of $9.2 \mathrm{mmol} / \mathrm{l}$ and creatinine $100 \mu \mathrm{mol} / 1$ at the time of admission. Gentamycin trough level after the third gentamicin dose was $7.9 \mathrm{mg} / 1$ (therapeutic range $<2$ $\mathrm{mg} / \mathrm{l})$. The differential diagnosis was between gentamicin nephrotoxicity, sepsis and hypoadrenalism secondary to amyloidosis.

Gentamicin and metoprolol were stopped. He responded to treatment with intravenous fluids, inotropes and intravenous antibiotics (initially flucloxacillin but later changed to erythromycin and ceftriaxone when what was assumed to be an antibiotic related rash and signs of pneumonia developed.) No fluid was detected on ultrasound examination of the hip performed within
24 hours of admission, gallium scan and triple phase bone scan did not support the suspicion of hip sepsis and as clinical features of pneumonia had developed joint aspiration was not performed. Opportunistic pneumonia was considered in the differential diagnosis but because he had no obvious risk factors for HIV, a normal lymphocyte count, and had not been receiving immunosuppression treatment for two years bronchoalveolar lavage was not felt to be necessary. Prednisolone $40 \mathrm{mg}$ was introduced to cover the possibility of hypoadrenalism although a subsequent synacthen test was equivocal (360 $\mathrm{nmol} / 1$ at time 0 but rising by less than 200 $\mathrm{nmol} / 1$ to $540 \mathrm{nmol} / 1$ at 30 minutes, normal rising by more than $200 \mathrm{nmol} / \mathrm{l}$ to greater than 500 nmol/1). Hydroxychloroquine was added for joint pain pending further investigation. More aggressive immunosuppression was considered. However, in light of the unreliability of our patient and the recent infective episode, it was felt that the risks outweighed the benefits at that stage. A short period of haemodialysis was required but by discharge 18 days later he was feverish, normotensive and passing urine spontaneously, creatinine was $271 \mu \mathrm{mol} / 1,24$ hour creatinine clearance $25 \mathrm{ml} / \mathrm{min}$ (normal range $80-130 \mathrm{ml} / \mathrm{min} / 1$ and 24 hour protein excretion $0.7 \mathrm{~g}$ albumin/day (normal range $<0.1 \mathrm{~g} / 24 \mathrm{~h}$ ). Improvement was maintained and when seen seven weeks later creatinine was $75 \mu \mathrm{mol} / \mathrm{l}$, although 24 hour protein excretion had increased to $3 \mathrm{~g}$ albumin/day and creatinine clearance was $24 \mathrm{ml} / \mathrm{min}$. Enalapril $2.5 \mathrm{mg}$ daily was introduced for developing hypertension.

Nineteen days later he was again admitted to the renal unit with a three day history of flu-like symptoms and generalised joint pain. Apart from enalapril he had not been given any new medication and denied any other self medication including illicit substances. $\mathrm{He}$ was feverish but hypotensive-blood pressure $70 / 40 \mathrm{~mm} \mathrm{Hg}$, musculoskeletal examination was unchanged and no obvious source of sepsis found. Investigations revealed white cell count $24.6 \times 10^{9} / 1$, (normal range $4-10 \times 10^{9} / 1$ ), urea $33.1 \mathrm{mmol} / \mathrm{l}$, creatinine $440 \mu \mathrm{mol} / \mathrm{l}, \mathrm{K}+5.8$ $\mathrm{mmol} / \mathrm{l}$ (normal range $3.5-5.0 \mathrm{mmol} / \mathrm{l}$ ) and creatinine phosphokinase $60 \mathrm{u} / 1$ (normal range $<150$ ). Enalapril and hydoxychloroquine were stopped because of the deterioration in renal function. Intravenous erythromycin was given empirically to cover a putative chest infection 
Table 1 Ecstasy toxicity and rheumatological differential diagnosis

\begin{tabular}{ll}
\hline Ecstasy adverse effect & Rheumatological differential diagnosis \\
\hline Seizures, psychiatric effects, organic cerebral damage ${ }^{3,4,9,10}$ & Cerebral lupus \\
& Cerebral vasculitis \\
& Drug adverse effects \\
Muscle pain,increased CK, rhabdomyolysis & Myositis \\
Abnormal liver function tests, hepatitis & Drug adverse effects, for example, SASP, MTX \\
& Hepatitis in association with autoimmune disease \\
Aplastic anaemia $^{11}$ & Related to autoimmune disease \\
& Related to DMARDs \\
Pyrexia & Disease activity (systemic onset JCA, SLE, etc) \\
& Infection \\
Renal failure & DMARD associated drug fever \\
& Nephritis in association with CT disease/vasculitis \\
& Progression of amyloid \\
& Drug adverse effects \\
& Scleroderma renal crisis \\
\hline
\end{tabular}

Disease modifying antirheumatic drug (DMARD), sulphasalazine (SASP), methotrexate (MTX), systemic lupus erythematosis (SLE), connective tissue (CT).

but stopped four days later when blood, urine and sputum cultures as well as viral and atypical serology were found to be negative. Haemodialysis was required for fluid overload. Two weeks later he developed spiking fever and abnormal liver function tests-alkaline phosphatase 1140 $\mathrm{u} / 1$ (normal range 70-200 u/l), total bilirubin 10 $\mu \mathrm{mol} / \mathrm{l}$ (normal range $2-22 \mu \mathrm{mol} / \mathrm{l}$ ) aspartate aminotransferase $97 \mathrm{u} / 1$ (normal range 12-48), alanine aminotransferase $111 \mathrm{u} / 1$ (normal range 3-55), and an increase in amylase at $1030 \mathrm{u} / 1$ (normal range 70-200 u/l) consistent with pancreatitis. Intravenous metronidazole and ceftriaxone were started and endoscopic retrograde cholangiopancreatography (ERCP) and sphincterotomy performed. Changes consistent with ascending cholangitis were seen and within 72 hours of sphinterotomy liver function tests had returned to normal. Just before the ERCP he spontaneously admitted to ingesting three ecstasy tablets along with an undisclosed quantity of amphetamine within three days of both admissions.

\section{Discussion}

Abuse of ecstasy (the amphetamine analogue 3,4-methylenedioxymetamphetamine (MDMA)) has increased over the past decade because of its pleasurable effects of increased sensuality, euphoria and closeness to others. In a 1996 survey of drug and alcohol abuse, MDMA use was reported by $13 \%$ of the 3075 second year university students questioned. Initially heralded as safer than alcohol, several dose independent fatalities have proved this not to be the case. ${ }^{2}$

Ecstasy induces dehydration resulting from increased sweating and urination, ${ }^{3}$ which can have serious consequences in a patient with pre-existing renal impairment. It seems probable that this was the mechanism of renal failure resulting in the second admission to hospital. It is less clear how much the ecstasy ingested before the first admission contributed to the fever and subsequent renal failure. In retrospect the gentamicin dose administered after this admission was sub-therapeutic even in the presence of renal impairment. A gentamicin level should have been checked before the second rather than after the third gentamicin dose. The high gentamicin trough level highlights the need for meticulous moni- toring of gentamicin levels in patients with suspected renal impairment and suggests the patient had oliguria that passed unnoticed during the first 36 hours of hospital admission. The ecstasy induced hyperthermic syndrome,${ }^{45}$ which is associated with fever, coagulopathy, rhabdomyolysis, and acute renal failure is unlikely as the creatine kinase was normal during both admissions.

Hepatotoxicity can occur after both isolated or during regular ecstasy abuse. The interval between ingestion and initial symptoms varies between one and four weeks. Liver function tests normally show increases in both bilirubin and transaminases. On stopping the drug liver function tests usually return to normal over a period of weeks. ${ }^{67}$ Liver biopsy appearances may mimic both viral and autoimmune hepatitis however smooth muscle antibody positivity has been reported on one occasion. ${ }^{7}$ Ecstasy was considered as a cause for the pancreatitis and liver function test abnormalities found in this case, however ascending cholangitis seems a more likely explanation in light of the rapid response to antibiotics and sphincterotomy.

It is our perception that children and adolescents with JCA have limited opportunities to take risks and because of overprotective parenting are denied freedom to experiment. Complications of drug misuse including HIV are therefore unlikely to be considered in the differential diagnosis when such patients are admitted to hospital. A recent American study found that $8 \%$ of 52 patients with JCA (mean age 13.9 years) had experimented with amphetamines and $30.7 \%$ had used alcohol, ${ }^{8}$ figures not dissimilar to those found in their healthy peers. It was also found that $65.4 \%$ never sought medical care without their parents, which may be one reason why counselling about the dangers of substance abuse is often neglected in this group of patients. In many cases ecstasy use is concealed as it is perceived by many to be safe, unless asked directly and in private away from relatives. Our patient also felt unable to admit to taking ecstasy because he was frightened that we would both absolve responsibility for his care and tell his parents. 
The lessons

- Ecstasy can cause adverse effects that may mimic exacerbations of rheumatic disease activity or toxicity secondary to disease modifying anti-rheumatic drugs (see table 1).

- A high index of suspicion must be maintained in any adolescent or young adult with rheumatic disease who becomes unwell for no obvious reason even if substance abuse is initially denied.

- The dangers of substance abuse must be highlighted, but in such a way to maintain trust and a confidential doctor patient relationship.

The authors would like to thank Mrs Margaret Tosh for help with the preparation of the manuscript.

1 Webb E, Ashton CH, Kelly P, Kamali F. Alcohol and drug use in UK university students. Lancet 1996;348:922-5

2 Schwartz RH, Miller NS. MDMA (ecstasy) and the Rave: A review. Paediatrics 1997;100:705-8.
3 Steele TD, McCann UD, Ricaurte GA. 3,4-Methylenedioxymethamphetamine (MDMA, "Ecstasy"): pharmacology and toxicology in animals and humans. Addiction 1994;89:539-51

4 O'Connor B. Hazards associated with the recreational drug "ecstasy" Br J Hosp Med 1994;52:507-14

5 Dar KJ, McBrien ME. MDMA induced hyperthermia: report of a fatality and review of current therapy. Intensive Care Med 1996;22:995-6

6 Fidler H, Dhillon A, Gertner D, Burroughs A. Chronic ecstasy (3,4-methylenedioxymetamphetamine) abuse: a recurrent and unpredicatable cause of severe acute hepatitis. J Hepatol 1996;25:563-6

7 Dykhuizen RS, Brunt PW, Atkinson P, Simpson JG, Smith CC. Ecstasy induced hepatitis mimicking viral hepatitis. Gut 1995;36:939-41

8 Nash AA, Britto MT, Lovell DJ, Passo MH, Rosenthal SL. Substance abuse among adolescents with juvenile rheumatoid arthritis. Arthritis Care Research 1998;11:391-6

9 Holden R, Jackson MA. Near fatal hyponatraemic coma due to vasopressin over-secretion after "ecstasy" (3,4-MDMA). Lancet 1996;347:1052.

10 Maxwell DI, Polkey MI, Henry JA. Hyponatraemia and catatonic stupor after taking ecstasy. BMJ 1993;307:1399.

11 Marsh JC, Abboudi ZH, Gibson FM, Scopes J, Daly S, O'Shaunnessy DF, et al. Aplastic anaemia following exposure to 3,4-methylenedioxymethamphetamine ("ecstasy") Br J Haematol 1994;88:281-5. 